\title{
CONSERVATION: IS IT JUSTIFIED IN THE PUBLIC INTEREST?
}

\author{
MAURICE J. SYCHUK*
}

One of the criticisms of the conservation program is that conservation does not promote public welfare but is a private price maintenance scheme. This article analyzes the achievements of the conservation program and concludes that although the effect of conservation is to stabilize existing prices, information available with respect to the rate of return on investment of oil companies would indicate that prices of crude oil and petroleum products are not inordinately high. This article also discusses the sources of economic inefficiency in the oil industry and suggests that efforts be taken to make conservation more efficient.

\section{A. DEFINITION OF CONSERVATION}

Probably the most quoted statement about conservation was made by President Taft who said that it is something a great many people are in favour of, no matter what it means." What does the word "conservation" mean? It is submitted that conservation must have a definition founded in economics, and in recent years economists have built up a body of theory on conservation that centres on maximizing social benefits over time by proper distribution of resource use over time. Professor Stephen McDonald, of the University of Texas, has summarized an economic definition of conservation "as action designed to achieve and maintain the optimum time distribution of use of natural resources."

From the above it can be seen that a working definition of conservation is almost identical with an accepted definition of economics as an effort to maximize revenues relative to costs. ${ }^{3}$ If this is true, no special theory of conservation is necessary and conservation consists of the application of the general theory of "economic efficiency" to the particular circumstances of the petroleum industry. On this basis the question to be resolved is whether the industry as organized under existing conservation regulation is "efficient," and, put in its simplest form the question is: "Are the costs incurred in producing the present amount of oil greater than they need to be?"4

From the standpoint of conservation, natural resources are divided into two categories, namely:

(a) Renewable resources, such as soils, timber, wild life, and stream flow.

(b) Nonrenewable resources, such as oil and gas.

Conservation of the first category of resources consists of safeguarding the basic conditions on which their renewability depends. Conservation of the second category of resources, generally the conservation of minerals, consists of prevention of waste, encouragement of reuse where

- B.A., LL.B. (Sask.), M.C.L. (Southern Methodist University), member of the Law Societies of Alberta and Saskatchewan, Assistant Professor, Faculty of Law, The University of Alberta.

1 Lovejoy and Homan, Economic Aspects of Oil Conservation Regulation, published for Resources for the Future, Inc. by The John Hopkins Press, Baltimore, 1967, p. 8. 2 Id., at 17.

3 Rhodes, "Engineering and Economics in Conservation." in (1967) 12 Rocky Mountain Mineral Law Institute 425, p. 428, makes the distinction between preservationists and conservationists by stating that economics is of no concern to the preservationist.

4 conservationists 
possible, and, in some cases, retardation of use. Because petroleum is destroyed or dissipated in its use, the principal form of conservation of oil and gas is the prevention of waste, although retardation of use of oil and gas has also been advocated on conservational grounds. ${ }^{5}$

Perhaps a few comments are in order on the question of whether our reserves of oil and gas. are being depleted at an excessively rapid rate. Given the existing excess producing capacity it is difficult to argue that present lower priority uses (e.g. an end-use of oil and gas that is below its "intrinsic" value) should be sacrificed in the interest of higher priority uses in the future. A pessimistic long run view is that our descendants are going to starve in any case, whereas an optimistic long run view is a belief that man will be able to solve problems of resource supply as they arise.

Having outlined the economic approach to conservation, let us take a look at the petroleum industry's concept of conservation. Zimmermann's definition of conservation is generally accepted by the industry:

... there are two major objectives of the present regulatory program: (1) the prevention of waste of oil and gas, through which the ultimate recovery of these products from their reservoirs is greatly increased; and (2) the protection and adjustment of correlative property rights appertaining to each owner of land in an oil or gas pool.

These two objectives have become the primary aims of petroleum conservation and regulation. [Emphasis in the original.] ${ }^{\circ}$

Zimmermann indicates that these two objectives are "coequals, each worthy of pursuit in its own right, one for the sake of what may be called economy, the other for the sake of equity."

It is submitted that Zimmermann's definition of conservation is an accurate description of the relevant provisions of the Alberta Oil and Gas Conservation Act ${ }^{*}$ and the Saskatchewan Oil and Gas Conservation Act. ${ }^{0}$ These sections are similar to the provisions of the Interstate Oil Compact Commission's Model Form for an Oil and Gas Conservation Statute, ${ }^{10}$ except that the Model Form makes it clear that in the event of a conflict between the prevention of waste and the protection of correlative rights, the duty to prevent waste is paramount. ${ }^{11}$

Perhaps it would be an interesting digression to illustrate the application of these two functions of prevention of waste and protection of correlative rights by a discussion of two provisions common to most conservation statutes; compulsory pooling and compulsory unitization. A spacing unit is defined as the maximum area that can be efficiently and economically drained by one well, ${ }^{12}$ and compulsory pooling refers to the bringing together by law (as opposed to the voluntary agreement of the parties) of all the separately owned interests within the spacing unit established by the conservation commission in order that the

5 The Gas Resources Preservation Act, 1956, S.A. 1956, c. 19, s. 4 provides that "the intent. purpose and object of this Act is to effect the preservation and conservation of the oll and gas resources of the Province and to provide for thelr effective utilization having regard to the present and future needs of persons within the Province."

i Zimmermann, Conservation in the Production of Petroleum, Yale University Press, New Haven, 1957, p. 24.

I Ibid.

s S.A. 1957, c. 63, ss. 4, 2(t), 2(u).

? R.S.S. 1965 , c. 360 , ss. $3,2(1), 2(p)$

10 1959. ss. $1.1 .1,1.1 .12,1.1 .14$.

10 Ibid., s. 3.2 .

12 Section 5.2 of the Model Form. See also Section 26 of the Saskatchewan Oil and Gas Conservation Act. 
owners may share in the production from the single well that will be allowed on the said spacing unit. Compulsory unitization is the bringing together, again by law, of the separately owned tracts in a pool (each tract may consist of several spacing units) into one fieldwide unit and operating the whole reservoir (in some cases a portion thereof) as a single unit. In compulsory pooling we are interested in integrating all the interests in a single spacing unit, and in compulsory unitization we are interested in integrating all the interests in a fieldwide reservoir. ${ }^{13}$

The purpose of pooling and unitization is to make possible the conservation of oil and gas through the prevention of waste. Pooling prevents waste in that it prevents excessive drilling which is wasteful both in terms of the cost of drilling unnecessary wells (economic waste) and in terms of unnecessary and undesirable dissipation of reservoir energy resulting in a loss of otherwise recoverable hydrocarbons (physical waste). Although unitization also prevents economic waste through the drilling of unnecessary wells, it is primarily intended to prevent physical waste by giving the reservoir engineers an opportunity to make the most efficient reservoir drive dominant, as well as an opportunity to engage in pressure maintenance operations, and thereby increase the recovery of the producible hydrocarbons.

In addition to the prevention of waste, compulsory pooling protects correlative rights where there are small tracts in the field. The owner of a tract of land too small to be entitled to a well permit under the applicable spacing rule is, nevertheless, entitled to a fair opportunity to produce the hydrocarbons in place beneath his land. If the spacing regulations are rigidly adhered to, the owner of a tract smaller than the drilling unit would either be denied a permit to drill, or he would be allowed to produce only the amount of oil and gas equivalent to that in place within the boundaries of his tract, in which case it may not be profitable for him to drill. In either event, the small-tract owner's oil would be drained away and produced by others. Alternatively, fixing an allowable for the well on the small tract large enough to make the well a profitable one would confiscate the property of the owners of neighboring tracts since much of the oil produced on the small tract would be drained from under the neighboring tracts without their owners being able to prevent it. ${ }^{14}$ There is only one just and reasonable solution to the problem and that is compulsory pooling.

Basic to our study of conservation is the necessity of distinguishing between two concepts of waste-that of the geologist and that of the economist. To the geologist waste is anything that reduces the amount of oil ultimately recoverable. On the other hand the economist views waste as any production which it would pay to postpone or forego. Perhaps the best illustration of the economic approach is that found in Stuart E. Buckley's discussion of the Maximum Efficient Rate of production, as follows:

1: Williams and Meyers, Oil and Gas Law, Volume VI, p. 68-69.

if In the absence of a compulsory pooling statute the Texas Railroad Commission adopted the latter alternative, and it was the decision of the Texas Supreme Court in the Normana case (Atlantic Refining Company v. Raitroad Commission (1961), 346 S.W. $2 \mathrm{~d} 801$ ) and in the Port Acres case (Halbouty v. Railroad Commission (1962), 357 S.W. 2d 364) striking down the advantages of small-tract drilling that led to the enactinent of a compulsory pooling statute. The Mineral Interest Pooling Act, Tex. Rev. Civ. Stat. Ann., Art. 6008 (c) (1965). 
Rates lower than such maximum may permit still higher ultimate oil recovery, but once the rate is sufficiently low to permit the basic requirements to be met, the incremental ultimate recovery obtainable through future reduction of the rate of production may be insufficient to warrant the additional deferment of $a$ return and the additional operating expenses that would result from a prolongation of the operation. A rate of production so low as to yield no return would obviously be uneconomic, of no advantage to the operators, and of no ultimate benefit. [Emphasis added] ${ }^{15}$

Although it has been popular to distinguish between physical waste and economical waste for purposes of conservation, the modern tendency is to equate the two under economic waste since the loss of otherwise recoverable hydrocarbons is economic waste in the negative rather than the positive sense. ${ }^{16}$

\section{B. ACHIEVEMENTS OF CONSERVATION}

\section{Qualitative Analysis}

No attempt will be made in this paper to trace the history of petroleum conservation as this subject has been extensively treated elsewhere. ${ }^{17}$ One of the strongest criticisms of the conservation program is that conservation does not promote public welfare but is a private price maintenance scheme. ${ }^{18}$ In his appraisal of oil and gas conservation, Zimmermann states the problem as follows:

In particular an effort will be made to determine whether the program serves the public interest, including the interest of the consumer, or whether it is, as some critics claim, a scheme for the enrichment of private interests at the expense of the public, passing under the guise of a social service. ${ }^{19}$

Discussing this controversy from the point of view of a qualitative appraisal of the achievements of conservation in the production of petroleum, Zimmermann concludes that the outstanding effect of conservation has been the virtual abolition of the earlier system of drill-andproduce-as-you-please.

Zimmermann submits that by abolishing the-old fashioned wasteful system of production and by substituting in its place controlled production at or below the Maximum Efficient Rate, conservation has greatly prevented physical waste and has thereby added to known reserves by increasing the amount of oil that is ultimately recovered from a reservoir, and, correspondingly reduced the need for new dis-

15 Buckley, Petroleum Conservation, American Institute of Mining and Metallurgical Engineers, New York, 1951, p. 151-52. See also Rhodes, Supra., n. 3, at 432, wherein he points out that unavoidable waste is always present in oil and gas operations and that the only means of absolutely preventing physical waste lies in closing down all oll and gas producing operations.

11 E.g. "Ideal conservation will result when the maximum hydrocarbon recovery is achieved within a reasonable time period and with a minimum expenditure." [Emphasis added]. Interstate Oil Compact Commission, A Study of Conservation of Oil and Gas in the United States, 1964, Oklahoma City, 1964, p. xvi. Because of the implications of Canadian Constitutional Law, the Alberta Oil and Gas Conservation Board was very careful to point out that waste meant physical waste and did not include economic waste, "although economic considerations enter into the determination of when physical losses become waste." Report and Decision on Review of Plan for Proration of Oil to Market Demand in Alberta, 1964, O.G.C.B. Report 64-10, p. 15.

17 For the history of conservation in the United States, see generally: American Bar Association. Section of Mineral Law, Conservation of Oil and Gas, $A$ Legal History. (1938): American Bar Association, Section of Mineral Law, Murphy, (ed.). Conservation of Oil and Gas, A Legal History, 1948, (1949); American Bar Assoclation, Section of Mineral Law, Sullivan, (ed.), Conservation of Oil and Gas, $A$ Legal History, 1948-58, (1960): Interstate Oil Compact Commission, The Compact's Formative Years, Oklahoma City, 1955. For the Canadian conservation background see: Interstate Oil Compact Commission Papers, Oil in Canada, 1952; Floyd K. Beach. History of Oil and Gas in Western Canada prior to 1947.

18 See Watkins, Oil: Stabilization or Conservation? A Case Study in the Organization of Industrial Control, Harper and Bros., New York, 1937. For a list of books dealing with a critical appraisal of petroleum conservation, see Zimmermann, Supra., n. 6, p. 4 .

19 Id., at 268 . 
coveries. But this is a long run effect, and in the absence of excess capacity the transition from uncontrolled to scientifically controlled production is likely to require a stepping up of exploration. In the long run, reserves are made to last longer, and ultimate exploratory effort can be relaxed. In this manner, conservation in the long run tends to lower costs. ${ }^{20}$

Another area considered by Zimmermann in his qualitative appraisal is the effect of conservation on petroleum prices. Zimmermann concedes that the effect of restricting production to market demand at a time when production in excess of market demand has reduced prices below actual $\operatorname{costs}^{21}$ is to increase prices, but contends that so long as such curtailment of supply does not hold the price at a higher level than the price a competitive market would have established, the interest of the consumer would appear to be protected."2 Unfortunately, there is no way of determining what the price of crude oil would have been in the absence of conservation.

Continuing his discussion of the effect of conservation on petroleum prices, Zimmermann points out that regulation avoided overproduction with its resulting depressed prices and thereby encouraged greatly improved and expanded exploitation of oil and gas reserves, and suggests that it is to the best interest of society that prices be not unduly depressed by overproducing, since it could be hardly expected that intelligent investors would be willing to risk the billions of dollars needed to develop petroleum supplies if they were constantly threatened with violent price fluctuations that would wipe out their investments. ${ }^{23}$

Perhaps Zimmermann's most persuasive comment with respect to the relationship between conservation and price is that when one is dealing with an irreplaceable natural resource such as petroleum, a wise policy governing the price of this energy source should not aim exclusively at reducing consumer prices to a minimum, but should be concerned with an adequate and stable supply of the same. ${ }^{24}$

After warning the reader of the difficulties which complicate the statistical determination of specific achievements creditable to conservation, Zimmermann turns to a quantitative measurement of the specific

20 Id., at 272

21 Following World War I there was a chronic oversupply of crude oll in the United States and the average price of crude oil fell from a little over $\$ 3.00$ a barrel in 1920 to $\$ 1.25$ a barrel in 1929 .

22 Supra, n. 6, at 273.

23 Id., at 274-75.

24 Id., at 273. Zimmermann would appear predisposed in favour of conservation, at $p$. 18 he states: "If in this book a position is taken in defence of government interference in the adjustment of supply to demand, it is done in the conviction that under the peculiar circumstances prevailing in the area of petroleum production, such government interference is needed to make the market process work constructively." At p. 110-11, Zimmermann lists the factors in the petroleum industry which necessitate conservation, as follows: "This conclusion rests on such indisputable facts as (1) the fluldity of petroleum, which is shared by no other mineral except, to a degree, water; (2) the vital role of gas in most reservolrs as the natural source of reservoir water; (2) the vital role gas in mast reserion-again a unique phenomenon: (3) the resulting need of controlled rates or volume of production; (4) diverse structural and other characteristics of reservoirs; (5) multiple ownership of reservolrs: and (6) the legal rules applicable to petroleum lands. If our property laws were different: if human nature were different; if petroleum were a solid; if the total resources were known, at least in general outline; if petroleum deposits were typically large instead of made up, as they actually are, of innumerable driblets, each of which must be discovered with the aid of a drill-then perhaps reliance on free competitive market processes might be justleted. But there is no escaping the facts as they are. And they processes misht be ustifled. But there is no escaping the facts as they are. And they do oppose in formidable array any presumption in favor of the free market processes and industry faces the aiternatives of practicing effective vol 
achievements of the petroleum industry under conservation and discusses five specific effects of conservation.

2. Quantitative Analysis

(a) Conservation and the amount of crude produced.

As stated above conservation has increased the amount of oil recovered. Robert E. Hardwicke, a long time student of conservation, made the following statement in 1952: "It is believed that regulations under State conservation statutes during the last twenty years have resulted in a recovery of perhaps $\mathbf{5 0}$ percent more oil than would have been recovered in the absence of regulations." ${ }^{23}$

(b) Conservation and increase in reserves.

As discussed above, Zimmermann is of the opinion that restricting production to reasonable market demand materially contributes to the accumulation of dependable reserves. ${ }^{24 i}$ Although this conclusion is contained in his section on quantitative analysis, he does not give a figure for the amount of increase in reserves. The increase in reserves is, of course, related to the increase in the amount of oil recovered discussed above, because conservation ensures that discovered reserves are efficiently produced.

(c) Conservation and well spacing.

Closely linked to the regulation of production of petroleum is the regulation of well spacing. Not only does the drilling of unnecessary wells greatly increase the costs of producing oil, but it also causes physical waste by the dissipation of reservoir energy and thereby decreases the amount of oil recovered. Hines $H$. Baker, President of Humble Oil and Refining Company, estimated that in 1947 wide well spacing in Texas, Louisiana, Mississippi and New Mexico alone saved the drilling of over 100,000 unnecessary wells. ${ }^{2 i}$

(d) Conservation and prices of crude oil and petroleum products.

The statistical material presented by Zimmermann indicates that petroleum prices have not risen faster than the general price level, and he concludes that the same is due to such factors as technological and managerial advances and to the cost-reducing effects of the conservation program. The technological changes have resulted in a fuller use made of the whole barrel of crude, whereas the conservation program has contributed to the fuller recovery of oil from the reservoir and to the avoidance of losses in storage and of waste in the drilling of too many wells. ${ }^{28}$

(e) Conservation and return on capital.

It is doubtful whether any unequivocal conclusions can be drawn as to the effect that conservation has had on the return on capital of oil companies and whether this rate of return has been excessive or out of line with the return on capital of other industries in the United States.

Zimmermann's analysis refers to a study prepared by National City

25 Id., at 277. See also footnote 7 on the said page where Zimmermann quotes from a letter from Robert E. Hardwicke dated December 6, 1954, as follows: "I really believe that ultimate recovery (including oil liquids from gas) as a result of conservation will be 100 percent more than would be receovered without conservation practice."

20i Id., at 279 .

$2 i$ Id., at 281 .

28 Id., at 291-98. See generally Cassady, Price Making and Price Behavior in the Petroleum Industry. Yale University Press, New Haven, 1964, p. 315-33. 
Bank, New York, showing the rate of return on investment for several industry groups for the period 1944-53. This study showed that the average annual return for all manufacturing concerns for the ten year period 1944-53 was 13.66 percent, while that for the oil companies was 13.98 percent. ${ }^{29}$ A more recent study by the First National City Bank of New York showed that the return on net worth of 107 petroleum companies in 1967 was 12.9 percent, as compared with the 12.5 percent average for manufacturing companies, and that over the ten year period 1958-67, the petroleum industry's return on net worth averaged 11.2 percent, slightly below the 11.8 per cent for all manufactuirng industries. $^{\text {so }}$ In viewing these figures it is well to keep in mind that all figures are average and that actual earnings of individual companies are considerably higher and considerably lower than the averages shown.

In concluding this evaluation of oil and gas conservation, perhaps it would be informative to quote Zimmermann's summary of his quantitative appraisal of the specific achievements of conservation as follows:

Admittedly, the exact effects of conservation on these five phases are more or less indeterminate. What evidence there is, appears favorable, in the sense that under conservation recovery of crude and gas seem to have improved, costs seem to have been reduced or at least their rise under the pressure of a trend toward diminishing returns has been retarded, prices of neither crude nor finished products appear to have risen faster than the general price level; on the contrary, viewed over a period of forty years, the trend is for these prices to stay below the general price index. In view of the risks involved in some, if not all, phases of the petroleum industry, the return on capital does not seem to be out of line with the general situation in manufacturing industries in the United States. ${ }^{31}$

and also to quote his conclusion of his appraisal of petroleum conservation as follows:

In summary, it may be said that not all accomplishments reasonably credited to petroleum conservation can be proved, statistically or otherwise. Much must be left to judgment, including appraisal of imponderables. The conclusion here reached is that on balance the conservation program yields net values to society in terms of greater availability of petroleum at lower costs and of greater stability of one of the leading industries of this nation. That all this may also contribute to the financial success of the petroleum industry is not denied. [Emphasis in orginal.] ${ }^{32}$

\section{EFFICIENCY AND CONSERVATION}

Having examined the achievements of conservation from a subjective point of view it might be interesting to evaluate petroleum conservation from an objective point of view by using the standard of economic efficiency. In determining how to analyze the effect of regulatory practices upon the economic efficiency of the industry as a whole, Lovejoy and Homan reached the following conclusions:

(1) If an oil reservoir is served by more wells than are necessary to drain it at any desired rate of production, it violates the criterion of economic efficiency.

(2) If a reservoir is developed by numerous surface owners when costs on units could be made lower and ultimate recovery made higher by unit operation, it violates the economic criterion.

(3) If the regulatory authority enforced rules of reservoir development that brought points (1) and (2) into conformity with the economic criterion, it would need to give little thought to the rate of production that would

29 Id., at 279.

30 Oil Facts, published by the Committee on Public Affairs, American Petroleum Institute, Vol. 10. No. 3. May-June, 1968.

31 Supra, n. 6 at 300.

32 Id., at 325 . 
correspond to the economic criterion. If drilling and operating costs were minimized by the rules of reservoir development, the self-interest of operators could be left to determine the economic rates of production and the economic level of investment in development, according to their best judgment based on present and anticipated costs and prices and the applicable rate of interest for discounting future net revenues. It is unlikely that a regulatory agency would be in a better position to exercise judgment on how to maximize the present value of known or estimated reservoirs. ${ }^{33}$

Lovejoy and Homan are quick to point out that the actual development of reservoirs has not conformed to the above principles of economic efficiency, nor do they suggest that all reservoirs be developed on the basis of economic efficiency, because they concede that there may be good social reasons for deviating from the same. They point out, however, that the advantages of these clearly defined tests are to identify deviations from them and to serve as a basis for considering whether the deviations are justified by special considerations. ${ }^{34}$

It should also be repeated that there is no single criterion to evaluate the success of conservation and that even the use of the economic factor will produce different results when looked at from different standpoints. If conservation is contrasted with the days of unrestricted drilling and production, the results are very favourable, but if one analyzes conservation with respect to the possibilities for lowering costs and increasing ultimate recovery, the results may not be so favorable. It is important to stress that there is this dual point of view, and that "it is not inconsistent to say that the regulations have done both economic good and harm in the past and may do so in the future." ${ }^{35}$

Lovejoy and Homan carry out their economic study of petroleum conservation by a detailed analysis of the following four aspects of the petroleum industry, namely: (1) Reservoir Development, (2) Excess Producing Capacity, (3) The Proration System, (4) The Crude-Oil Market and Pricing Mechanism.

\section{Reservoir development and efficient recovery.}

It is universally recognized today in expert quarters that the most efficient way to develop a reservoir is to treat it as a single producing unit. ${ }^{36}$ The development programs of foreign fields held under concession agreements amply illustrate this principle. There appear to be many obstacles to unit operation by voluntary agreement, ${ }^{37}$ and as a result, compulsory (statutory) unitization appears to be the answer. Eugene V. Rostow, then professor of law and economics at Yale University, came to the following conclusions in 1948:

The author is one of those who have come to the conclusion that the rule of capture has proved, for this perhaps among other reasons, a socially undesirable rule of law, and that it should be changed as the root idea of our system of oil law. The preferable way to change it, however, is to impose unitary operations on the fields, rather than to undertake further experiments with the cumbersome, expensive and unsatisfactory plan of prorationing. The compulsory operations of all fields as units of production could be accomplished by requiring the organization of companies or co-operatives in which all surface owners would share on an equitable basis, either in proportion to their surface

s3 Supra, n. 1 at 23.

34 Ibid.

35 Id., at 56. Antitrust Laws et al. v. Unit Operation of Oil and Gas Pools, American Institute of Mining and Metallurgical Engineers, Dallas, 1961.

37 Buckley, Id., at 288-92. 
ownership or to the richness of underlying deposits. Oil production under such units could altogether eliminate the possible wastes associated with offset drilling and the other consequences of the rule of capture, as well as the many geologists' criticisms of the administration of proration laws. It would for the first time permit the number of wells to be kept to a minimum, and the flow from individual wells in the field to be determined by geological criteria rather than the accidental pattern of ownership of the land over the oil. The unitary operation of the oil fields is the only course of action which as a practical matter could permit high standards of conservation practice to be seriously followed. [Emphasis added.] ${ }^{38}$

The advantages of unit operations are as follows: (1) the saving of development expense by drilling fewer wells, (2) the saving of operating expense because of fewer wells, (3) enlarged ultimate recovery due to efficient use of the driving mechanism, and (4) early introduction of pressure maintenance schemes. To this case, economists commonly add the argument that, if all reservoirs were unitized, probably the whole apparatus of production control and proration could be dispensed with. If unit operation had been universal from the start, the level of production could be left to the application of business principles within a system of free markets. ${ }^{30}$ Lovejoy and Homan's conclusion: the petroleum industry seriously fails the test of economic efficiency in regard to reservoir development and recovery.

2. Excess producing capacity and related problems.

Although the statement is often made that the United States is not adding to its net crude oil reserves as fast as it used to, it appears that both the United States and Canadian oil industries have and will continue to have substantial excess producing capacity for several years to come. A most difficult problem appears to be facing the industry: Is it possible to increase the "reserve-life index" (the ratio of reserves to production) without generating additional excess capacity?

Applying the test of economic efficiency (defined as cost outlays no larger than are necessary to achieve a given production result) Lovejoy and Homan conclude that there is a great form of economic waste in the petroleum producing industry because of the great excess of investment in producing facilities. ${ }^{40}$ It is true that there are innumerable instances throughout the economic system as a whole of economic waste because of excessive investment, e.g. unnecessary filling stations, but what differentiates the petroleum industry is that it is already regulated and that existing conservation statutes in effect require operators to make wasteful investments as a necessary condition for capturing a share of the total market.

At the same time, by restricting production to market demand, the conservation authorities support prices that make the investment profitable. Commenting on this situation Lovejoy and Homan conclude that:

. . relatively high-cost firms can continue to exist under the price "umbrella," while low-cost firms reap substantially higher profits. If, at the same time that supply is being limited and prices held up, entry by new firms into the industry is possible, then the entry of those firms will lead to excess capacity in the industry and to some loss of output and earnings by those already in it. While additional investment adds up to an accumulation of idle capacity, this need not prevent the new investment from being remunerative to the owners as

38 Rostow, A National Policy for for the Oil Industry, Yale University Press, New Haven, 1948 , p. 45.

89 Supra, n. 1 at 79.

40 Id., at 115 . 
long as they are provided with production quotas that will provide revenues large enough to more than cover their costs. In the same way, older high-cost firms are not driven from the industry as long as the revenues from their quotas exceed their mere operating and maintenance costs. A "normal" return on their past "sunk" investment is not required to keep them alive and it may, indeed, have long since been recovered.

The tendency in such a system, if demand does not rise to validate larger productive capacity, is in the direction of a stalemate. Higher unit costs and lower anticipated profits on investment in new capacity will induce declining development outlays; this in turn, unless offset by some special stimulative measures, will also carry down exploratory investment. A firm rise in demand, permitting larger quotas, can only salvage the profit prospects temporarily. Higher profits would again stimulate drilling and the consequent growth of capacity. The only approach to keeping new investment profitable is through lower costs-an approach that would lead in the direction of greater economic efficiency through reducing the amount of investment in the idle capacity. [Emphasis added.] ${ }^{41}$

In its simplest form the problem is three pronged of how, simultaneously, to (1) introduce efficient low-cost development of new reservoirs, (2) reduce excess capacity, and (3) retain strong inducements to exploration. ${ }^{42}$

3. The proration system and related problems.

(i) Depth-bracket allowables:

A survey of market demand states in the United States shows that allocation formulas are all based upon depth factors adjusted in greater or lesser degree by an acreage factor. ${ }^{+3}$ The only explanation for the use of depth-bracket schedules in allocation formulas is the economic argument that deeper drilling and production are more costly and as a result, greater incentives, in terms of higher allowables, are required to bring forth the exploration and development of deeper horizons. Examining this rational for depth-brackets, Lovejoy and Homan point out that existing depth-bracket formulas do not accurately take into account differences in drilling costs at different depths, and that as a result, a depth factor schedule for allowables serves primarily as an administrative convenience, and conclude their discussion of depthacreage schedules as follows:

We can think of only two alternatives for which a clear rationale could be stated: (1) a modification of the present formulas with much more careful attention to the cost and other factors that enter into the formula; or (2) an entirely different system based upon MER ratings regardless of depth; or possibly (3) a combination of (1) and (2). To operate a market-demand proration system, it is necessary to have some base from which to calculate production allowables. What seems odd about the present system is the highly arbitrary character of the base.44

(ii) Marginal (Stripper) Wells:

These are old wells which have been reduced to pumping after substantial dissipation of the natural driving energies, or are new wells in poor structures or along the edges of better structures. ${ }^{45}$ In the United States marginal wells are exempt from the proration system because of their low producing capacity. The major complaint is that these high cost low capacity wells stay alive solely because of the combined effects of restricted production and the maintenance of a relatively

41 Id., at 116-18.

42 Lovejoy and Homan's suggested solutions to these problems are outlined, Infra, p. 367. 43 Supra, n. 1 at 141-167.

it Id., at 172 .

15 The National Stripper Well Association defines stripper wells as those averaging 10 barrels or less per day, or in fields averaging 10 barrels or less per well per day. 
high stable price level, whereas production from higher capacity lower cost wells is cut back to make room for these marginal wells. The essence of the problem is that of gradually transforming production from high-cost to low-cost sources and the difficulties are twofold: (1) Should production be shifted from stripper wells to more efficient wells? (2) How to avoid adding to the number of stripper wells in the future?

The standard answer of the petroleum industry to critics who suggest that some stripper wells be abandoned is that substantial reserves underlie these fields and to lose these reserves would create great physical waste. Lovejoy and Homan have three comments in this regard:

(1) If an orderly program of phasing out stripper wells could be devised, a substantial quantity of the stripper reserves would still be economically recoverable, particularly if the number of producing wells in each stripper field (and hence their cost of operation) could be eliminated. (2) The abandonment of certain stripper fields and their reserves would be likely to result in an improved financial status for the producing industry and for flush wells in particular. This in turn would increase incentives to exploration and might produce far more reserves at lower cost than the preservation of some of the stripper reserves. Such judgments are conjectural since no one knows the costs and capacities of existing or new wells. (3) If Adelman's figure 6 on the social cost of stripper wells is anywhere near correct, and we make no judgment here on its accuracy except to note that the cost must be substantial, the same amount of liquid-energy supplies felt to be so necessary for national security could quite possibly be developed through a subsidy of a lesser amount to exploration or to the oil shale industry. ${ }^{47}$

Discussing the question of whether it is worthwhile incurring the trouble involved in a positive policy of eliminating stripper wells, Lovejoy and Homan conclude as follows:

It would be difficult to justify the damage to vested interests unless some demonstrable public good were to ensue. Whatever the hypothetical merits of greater economic efficiency, expressed in lower average industry costs, no particular advantage would accrue to the public if the sole result were somewhat higher profits to the remainder of the industry. A public advantage would only appear if higher profits led to more active exploratory effort or if lower costs led to lower prices. [Emphasis added.] ${ }^{48}$

Dealing with the second half of the problem of how to avoid adding to the number of high cost inefficient stripper wells in the future the authors maintain that the same would be the consequence of a program of efficient reservoir development through wide well spacing and compulsory unitization. ${ }^{49}$

\section{(iii) Secondary recovery:}

In some states secondary recovery projects ${ }^{50}$ are exempt from market demand restrictions on the basis that they prevent physical waste by recovering a larger percentage of the oil in place. A major criticism is that secondary recovery projects further undermine the regulatory system by adding to the excess producing capacity. The issue is whether relatively low incremental cost primary production should be restricted in order to make room for relatively high incremental cost secondary production and Lovejoy and Homan feel that the economics of the situation should govern and point out that there is, in view of existing

46 M. A. Adelman, "Efflciency of Resource Use in Crude Petroleum," Southern Economic Journal, Vol. 31 (October, 1965), p. 101-22 estimates that an end to drilling of marginal wells would result in an annual saving for the United States of $\$ 2.5$ billion.

t; Supra, n. 1 , at 193 .

48 Id., at i94.

49 Ibid. maintenance schemes introduced at an early stage of reservoir development. 
overcapacity, no urgency to develop secondary recovery projects and that so long as the same remain accessible they can be developed or not as economic circumstances warrant. ${ }^{31}$

\section{The crude oil market and pricing mechanism.}

One of the most difficult aspects of petroleum conservation is its relationship to crude oil field prices. The historical evolution of conservation indicates that market stability was a major if not the primary reason for regulation in the 1930's. This was at a time when overproduction had unduly distressed the price of crude oil. This is not however, true today; the present system supports (stabilizes) prices but it does not actively attempt to revise prices. As overcapacity developed it was prevented from having a depressive effect on prices by the market demand proration process. The tendency of the system is thus to have a ratchet effect by which prices when they have risen are prevented from falling. ${ }^{52}$

It is extremely difficult to get an understanding of the market forces affecting crude oil prices. Purchasers must post field prices that assure them of long-run supplies of oil. One of the most important effects of the posted pricing system is that it facilitates crude oil exchange among the major purchasers. While it is true that price stability characterizes crude oil markets all crude does not move at posted prices. Premiums and discounts may be used to attract or discourage suppliers depending on the market conditions. Often a purchaser will deem it wiser to give a premium that he can drop relatively easily rather than raise the posted price. If discounts or premiums become widespread in an area they will reflect a corresponding change in the posted price.

The most complicated factor in crude oil prices is the fact that many purchasing companies also produce oil. On this point Lovejoy and Homan make the following observations:

In a field in which a purchaser owns substantial production (but not all of it), there may be an incentive to post a high price. The incentive comes from a judgment on the part of the company to take more profits at the producing level and less at the manufacturing or refining level. Crude-oil inputs to a refinery are a cost, and the owned production in this input is charged as a cost of refining in an interdepartmental book transaction. A high cost of selfproduced crude means a high refining cost, but it may also mean a high profit in production. A dollar of before-tax profit in production yields a greater after-tax profit than a dollar of before-tax profit in refining. Such a statement is a considerable oversimplification but seems to be generally true. The reason for this is the presence of special federal income tax treatment of expenses in and revenues from drilling and production. Whether this is a motivating force in posting higher prices in some fields by some purchasers, we do not know. It would seem, however, to be a logical profit-maximizing behavior for an integrated company. [Emphasis added.] 33

\section{SUGGESTED SOLUTIONS TO THE INEFFICIENCY OF THE OIL INDUSTRY}

In the course of their study Lovejoy and Homan identify the above described four interrelated but separable sources that define the nature of the industry's inefficiency. Repeating them they are (1) excessive

51 Supra, n. 1, at 195-202.

52 Id., at $237-43$.

53 Id., at 248. See generally, M. G. de Chazeau and A. E. Kahn, Integration and Competition in the Petroleum Industry, Yale University Press, New Haven, 1959, p. 221-29. 
capital investment, (2) excessive producing capacity, (3) inefficient reservoir development, and (4) proration rules that favor the production of high cost oil.st Lovejoy and Homan's suggested solutions to each of these sources of inefficiency are as follows:

(a) Excessive costs:

The excessive costs of the industry, it is submitted by Lovejoy and Homan, are of two sorts. Firstly, capital costs are inflated because more wells are drilled than are necessary, and secondly, all these wells entail operating costs. The authors feel that this can be resolved for prospective fields, firstly, by more efficient well spacing, and secondly, by removing from the depth-acreage formulas the incentives to drill development wells.

The reduction of costs through wider well spacing speaks for itself, but with respect to the incentives under existing proration schemes to drill development wells because of the well factor operative in the depth-acreage schedules, the authors make the following suggestion:

An alternative is to replace these schedules with something like MER regulations. The major complaint against an MER basis for allowable is that in times of severe restriction, fields with high MER's get the lion's share of allowed production and low-MER fields become unprofitable. Resort to yardsticks in times of stress is merely a scramble by low-MER producers to stay alive. If our interpretation is correct, it means that a more rational basis for allocation, such as the MER (and there may be other devices as good or better than MER's), awaits a serious move to resolve the overcapacity problem.5s

(b) Excess capacity:

The authors concede that overcapacity may be the normal situation for the industry, since given the existing price stability, profits become supranormal with an increase in allowables and are a great inducement to those with funds to invest to drill new wells and thereby add to the capacity.

The authors submit that the excess capacity problem is not insoluble, but that any workable solution must be drastic and requires substantial changes in regulatory practices and legislation. They make the following suggestions to reduce excess capacity:

(1) For new fields it might be feasible to shut in newly discovered reservoirs after minimal drilling to establish the reserves, and reward the investment by payments for "nonproduction" similar to the U.S. "soil bank" farm program.

(2) Another possibility along these lines would be to permit exploration and development to occur only on very wide spacing. Infill drilling would be prohibited.

(3) Another approach is the deliberate reduction of producing capacity in old fields. ${ }^{56}$

(c) Inefficient reservoir development:

A thorough going effort to place the industry on an economically efficient basis would require the introduction of compulsory unit operations in most reservoirs. In this regard it is interesting to note that Texas is finally contemplating compulsory unitization legislation. ${ }^{5 i}$ In

\footnotetext{
54 Supra, n. 1, at 265.

55 Id., at 267 .

50 Id., at 268-271.

si The Oil and Gas Journal, April 15, 1968, p. 39.
} 
Alberta, consideration may be given to proclaiming Sections 75 to 82 of of the Alberta Oil and Gas Conservation Act.

(d) The bias towards high cost oil:

Lovejoy and Homan conclude that existing conservation legislation seems to be designed with the purpose of getting as much as possible of the allowed oil production from the highest cost wells as is evidenced by (1) the unlimited production allowed to exempt wells, and (2) the way in which proration systems favor production from the less productive wells. This is the result of a proration system that permits far more wells to be drilled than are necessary for efficient drainage and protects their profitability. The solution: reduction of the number of wells as suggested under the heading "excessive costs" above. ${ }^{58}$

\section{E. SUMMARY AND CONCLUSION}

From the above analysis there would appear to be little, if any, doubt that conservation has prevented waste-has it at the same time supported unduly high prices of crude oil and petroleum products? Keeping in mind that we are dealing with the supply of a nonrenewable natural resource, the information available with respect to the rate of return on investment of oil companies would indicate that crude oil prices are not inordinately high. From the above analysis, there would also appear to be little doubt that the conservation program is not as efficient as it could be, and it is suggested that we concentrate our efforts on making conservation more efficient.

The above summary and conclusion is not very detailed nor conclusive, as the propose of this paper is to provide the seminar participants with an outline of the studies that have been conducted into the effects of conservation. It is hoped that this paper will enable the seminar participants to form their own evaluation of the conservation programs of the Provinces of Alberta and Saskatchewan by serving as the basis for discussion with the Chairmen of the Oil and Gas Conservation Boards of the Provinces of Alberta and Saskatchewan. 